\title{
SUBSIDIARIDAD, CONTRADICCIONES NACIONALISTAS Y RELACIONES DEL SISTEMA POLÍTICO CATALÁN CON EL ESPAÑOL (1931-1936): CUATRO SESIONES DEL PARLAMENTO AUTÓNOMO
}

\author{
ARNAU GONZÁlEZ I VilalTA
}

Universitat Autònoma de Barcelona

RESUMEN: El presente artículo analiza las relaciones entre la política catalana y la española a lo largo del periodo republicano (1931-1936). A partir de cuatro sesiones del Parlamento de Cataluña de gran significación, se analiza la evolución de la política catalana, que a lo largo de estos años se pudo haber diferenciado de manera destacada de la española. Contrariamente a esta posibilidad los principales partidos catalanes, ERC y la Lliga, buscaron en Madrid los apoyos y el escenario que les permitiera consolidarse o recuperar el poder en Cataluña. Así, en los seis años que transcurrieron entre la proclamación de la República y el inicio de la Guerra Civil, el catalanismo mayoritario, tanto de izquierdas como de derechas, no construyó una política propia diferenciada de la española sino que se vinculó cada vez más a ella.

Palabras Clave: Parlamento. Catalanismo. Subsidiaridad. Autonomía.

ABSTRACT: This article analyse the relations between Catalan politics and Spanish ones during the republican period (1931-1936). Starting on four sessions of great importance at Catalan Parliament it is been analysed the evolution of Catalan politics. Contrary to the possibility of distinguishing the Catalan politics to the Spanish ones, the principal Catalan parties, ERC and the Lliga, searched in Madrid the support and scenario that could help them to consolidate or recover the power in Catalonia. In this way, during the years between the proclamation of the Republic and the beginning of Civil War the majority catalanism, as much on the right as on the left, didn't build it own politic differentiated to the Spanish but linked itself, each time, more with Spanish politics.

KEY WORDS: Parliament. Catalanism. Subordination. Autonomy. 


\section{INTRODUCCIÓN}

Cuando el 14 de abril de 1931 los resultados de los comicios municipales convocados por el general Berenguer derivaban en la proclamación de la II República Española, en Cataluña se daba inicio a la consolidación de un sistema de partidos propio y diferente del general del conjunto del estado ${ }^{1}$. Larvado a lo largo de los últimos años de la Dictadura de Primo de Rivera, la política catalana, marcada sin lugar a dudas por el factor nacionalista y autonomista, diseñó un mapa de fuerzas políticas basado cada vez más en un fuerte bipartidismo, que se consolidaría a lo largo del período republicano y que vería su fin en estallar la guerra en julio de $1936^{2}$.

Así, la victoria obtenida en las principales ciudades catalanas y por encima de todo en Barcelona por una nueva fuerza política nacida solo un mes antes, la Esquerra Republicana de Catalunya, transformó de manera absoluta y sorprendente el panorama político catalán. Y es que la debilidad tradicional de los diferentes proyectos republicanos, catalanistas y de izquierdas que a lo largo de los treinta años previos había caracterizado la política catalana, ahora veían resarcirse de su fracaso histórico. Hasta ese momento el catalanismo, casi monopolizado por los sectores conservadores de la Lliga Regionalista de los Prat de la Riba y Cambó, quizá más por efectividad organizativa que no por su discurso, había derrotado sin problema todos los intentos de construir un partido nacionalista de izquierdas con suficiente fuerza para discutir el dominio regionalista. Además no se puede olvidar que junto a los regionalistas y los republicanos catalanistas, los grandes dominadores de la política catalana, si observamos por ejemplo la evolución de las actas de diputados a Cortes en el período 1901-1923, eran sin lugar a dudas los monárquicos y los radicales de Alejandro Lerroux.

Por esto, cuando un partido como era ERC que se presentaba a las elecciones sin apenas discurso y con el solo argumento de propaganda de un Macià casi mitificado por sus constantes intentonas independentistas contra la monarquía de Alfonso XIII (complot del Garraf y hechos de Prats de Molló), logró ganar y proclamar la República Catalana como estado integrante de la Federación Ibérica, la historia de Cataluña daba un decisivo cambio de rum-

1 Para un análisis general del sistema de partidos políticos en Cataluña durante la II República, ver: MOLAS, I.: El sistema de partits polítics a Catalunya (1931-1936), Barcelona, Edicions 62, 1972. También son muy útiles los artículos de RIQUER, B.: «El sistema de partidos políticos en Cataluña durante 1 primer bienio republicano (1931-1933)», en Historia Contemporánea, UPV/EHU, n. 6, (1991), pp. 85-95; y para el segundo bienio BALCELLS, A.: El sistema de partidos políticos en Cataluña entre 1934 y 1936, en La II Republica española, Bienio rectificador y Frente Popular, 19341936, IV Coloquio de Segovia sobre Historia Contemporánea de España, Madrid, Siglo XXI, 1988, pp. 83-105.

2 Para conocer el porque de los resultados del 14 de abril de 1931 en Cataluña, ver: UCELAY DA CAL, E., «Las raíces del 14 de abril en Cataluña», en Historia Contemporánea, UPV/EHU, n. 1, (1988), pp. 69-95. 
bo ${ }^{3}$. Hecha minutos después de que Lluís Companys proclamará la República «sin apelativos» en el balcón del Ayuntamiento de Barcelona, la política de hechos consumados de Macià daba el pistoletazo de salida al largo camino que conduciría a la consolidación de la autonomía que aprobarían las Cortes Constituyentes en setiembre de $1932^{4}$.

De este modo se constituía un sistema de partidos políticos catalán que se podría calificar de pluripartidista, ya que a las fuerzas de carácter general español existentes en Cataluña como el Partido Radical o el PSOE, debilitadas y casi inexistentes en el período 1931-1936, se inserían un amplio abanico de fuerzas caracterizadas por el intento de representar los diferentes sectores sociales con el común denominador del factor catalanista. Así, Esquerra, verdadero proyecto de partido interclasista de masas, intentaba englobar en sus filas a la pequeña burguesía urbana y rural, a los sectores moderados y radicales del nacionalismo catalán y hasta a una parte de la clase obrera; por su parte la Lliga Regonalista, descolocada y en «choc» desde abril de 1931, se erigiría cuanto menos hasta 1934 en el referente de los sectores más conservadores y de la alta burguesía industrial y rural. Al lado de estas dos formaciones, verdaderas constructoras del bipartidismo cada vez más acentuado de la política catalana, existían otros partidos que vivían a remolque de los dos grandes: la Unió Socialista de Catalunya (USC), escisión del PSOE, que se coaligó durante el período republicano a ERC dado su falta de influencia en la clase trabajadora dominada por la CNT; el Partit Catalanista Republicà (PCR, antigua Acció Catalana) que se situó en una posición intermedia entre ERC y la Lliga que lo llevaría al fracaso más absoluto; en último lugar la Unió Democràtica de Catalunya (UDC), primera formación demócrata cristiana de la historia de Cataluña y de un nacionalismo radical intentaría sin conseguirlo ganar sectores afines a la Lliga ${ }^{5}$.

Con este mapa político, una vez que la negociación entre el gobierno provisional de la República y el gobierno catalán convenció a Macià de renunciar a la República Catalana a cambio de la Generalitat y la promesa de la aprobación de un Estatuto de Autonomía en las Cortes Constituyentes, se iniciaba por primera vez la construcción de una política catalana diferenciada de la española ${ }^{6}$. Un fe-

3 Para un exhaustivo estudio de ERC, ver IVERN i SALVÀ, M. D.: L'Esquerra Republicana de Catalunya, 1931-1936, 2 v., Barcelona, Publicacions de l'Abadia de Montserrat, 1988; y también SAlLÉs, A.: Quan Catalunya era d'Esquerra, Barcelona, Edicions 62, 1986.

4 Para una crónica coetánea de los hechos en Barcelona es excelente el número 69 de mayo de 1931 de la Revista de Catalunya, dirigida por el historiador Ferran Soldevila.

5 Para conocer a fondo la evolución de la Lliga Regionalista, es imprescindible la obra ya clásica de Molas, I.: Lliga Catalana, 2 v., Barcelona, Edicions 62, 1972. Para el resto de partidos también existen estudios monográficos como el de BARAS, M.: Acció Catalana 1922-1936, Barcelona, Curial, 1978; o el de Raguer, H.: La Unió Democràtica de Catalunya (1931-1939), Barcelona, Publicacions de l'Abadia de Montserrat, 1976.

6 La renuncia a la República Catalana provocó grandes críticas de los círculos independentistas, especialmente centradas en la figura de F. Macià, líder de Estat Català. Un ejemplo de esta visión fue el libro de CaSals, J. i Arrufat, R.: Catalunya poble dissortat, Barcelona, J. Vila Fontseré, 1933. 
nómeno que vendría a reforzarse cuando el 15 de setiembre de 1932 las Cortes Constituyentes, donde ERC tenía treinta diputados que daban un apoyo imprescindible a los gabinetes presididos por Azaña desde finales de 1931 hasta setiembre de 1933, aprobaban el Estatuto y la consiguiente apertura del Parlamento de Cataluña.

La apertura de una cámara propia donde discutir la política catalana y legislar en los ámbitos de competencias concedidos por el Estatuto podía indicar la cada vez mayor separación respeto de la política general española, no sin olvidar los necesarios contactos para la consecución de los traspasos, etc., que habían de consolidar la aplicación del Estatuto. No obstante, y este es el objetivo del presente artículo, a lo largo del período 1932-1936 la cámara catalana vivió diferentes debates en los que se pudo contemplar la más que evidente subsidiaridad que los partidos catalanes y su política mantenían respeto al juego de mayorías y minorías de las Cortes generales. Al revés de lo que podían manifestar ciertos sectores de la política española del momento, la consolidación de un sistema de partidos catalanes separado del español, y la construcción de un espacio de tanta importancia como un Parlamento propio, no se tradujo en la aparición de una política catalana separada. Así, a partir de cuatro de las más significativas sesiones del Parlamento catalán en este sentido explicaremos las más que importantes vinculaciones españolas de los partidos catalanes y su política. La utilización de las alianzas españolas, de los resultados de las elecciones a Cortes, etc., para la batalla en la política catalana. Un período en que Barcelona se erigiría en un contrapoder a Madrid, en un nuevo centro de promoción política y funcionarial. Pero que al mismo tiempo verá como los partidos catalanistas no sabían o no querían abstraerse de las disputas generales españolas. Intervención en la política española general y demandas de no injerencia en Cataluña: las contradicciones del catalanismo se harán más evidentes cuando el objetivo primordial del Estatuto ya se hubo conseguido.

Es evidente que el análisis que aquí presento puede ser cuestionado desde dos ángulos compatibles. En primer lugar, se podría hablar de intervencionismo catalanista en la política general española como posición política no subsidiaria, sino todo lo contrario. Siguiendo las posiciones de catalanistas conservadores como Enric Prat de la Riba o Francesc Cambó en la política española, no sería nada extraño si habláramos de lo que Enric Ucelay da Cal a calificado de imperialismo catalán ${ }^{7}$. Pero visto desde una posición estrictamente nacionalista, lo que hicieron los políticos catalanes de la década de los treinta fue frenar constantemente las posibilidades soberanistas para esperar al curso de los acontecimientos españoles, entroncando de esta manera con los proyectos iberistas y federalistas del catalanismo histórico. Unos proyectos plasmados en diversos libros publicados en 1930 como La Concòrdia de Francesc Cambó o el del menorquín catalanista M. Rubió i Tudurí, que en una obra titulada Estat Espanyol. Societat Anònima escribía:

7 UCElay DA CAL, E.: El imperialismo catalán, Barcelona, Edhasa, 2003. 
«este libro no trata el catalanismo como un problema del Estado Español que se haya de solucionar - lo trata como el estimulante, el levado vital, el estímulo que hace y ha hecho más grande Cataluña y, con ella, la España que nos quiera seguir» ${ }^{8}$.

Por otro lado, también puede objetarse una posición que sitúe la política catalana como un elemento indisociable de la política española. Y esto es precisamente lo que en las siguientes paginas pretendo analizar. Porque no era tan previsible, que una política como la catalana que llevaba treinta años en pleno conflicto territorial, siempre teniendo en cuenta las inmensas masas obreristas ajenas a este debate, y que hacía de su catalanismo y catalanidad un elemento de diferenciación, no conllevara una evolución cada vez más desvinculada de la española una vez pudiera discurrir por sus propios foros de debate y decisión política9.

Por otro lado, es sabido que el independentismo catalán de ese período era débil y en constante crisis y que el nacionalismo mayoritario en la sociedad catalana de esos años era muy equivoco en sus definiciones nacionales, pero no tenia porqué presuponerse un camino de mayor vinculación ${ }^{10}$. Bien podría haberse producido lo que en otros casos en los que la autonomía concedida por el estado central a regañadientes, se transformaría en el primer escalafón del camino hacía la independencia o secesión. Por lo tanto, se trata de explicar el porqué de la no deriva independentista de la política catalana, teniendo en cuenta hechos como la proclamación de la República Catalana el 14 de abril de 1931 o la proclamación del Estado Catalán el 6 de octubre de 1934 por citar los dos ejemplos más significativos.

\section{El Parlamento de Cataluña: Sesiones Del 14 Y 20 DE DiCiembre De 1932}

Era evidente, y en esto insistieron muchos de los adversarios del Estatuto como Antonio Royo Villanova, los diputados del PSOE, o Ortega y Gasset, que la existencia de un Parlamento de Cataluña daba una cuota de soberanía nunca conocida desde el Decreto de Nueva Planta de Felipe V en 1716 que

\footnotetext{
8 RUBió i Tudurí, M.: Estat Espanyol. Societat Anònima, Barcelona, 1930, p. 222.

9 Para una visión inicial de la trayectoria del Parlamento de Cataluña durante la II República, ver entre otras obras las de PITARCH, I.: Sociología dels polítics de la Generalitat (1931-1939), Barcelona, Curial, 1977; también del mismo autor, La Generalitat de Catalunya. I. Els governs, Barcelona, Undarius, 1976.

10 Para la cuestión de la debilidad del independentismo catalán ver UCELAY DDA CAL, E.: «La crisis dels nacionalistes radicals catalans (1931-1932)», en Recerques, (Barcelona), n. 8, (1978); también es de gran utilidad el libro de RuBIRALTA, F.: Una bistòria de l'independentisme polític català, Barcelona, Pagès editors, Lleida, 2004, p. 63-110.
} 
ponía punto y aparte en la historia del parlamentarismo catalán ${ }^{11}$. Este espacio de debate político y de legislación exclusivamente catalana, podía generar en cierta lógica una tendencia de los partidos catalanes a centrar su actividad de Catalunya endins, y dejar en un lugar secundario su participación en la política española. Este fenómeno, que en cierta manera se produjo a partir de la aprobación del Estatuto, solo debe acudirse al discurso del jefe de la Minoría de ERC en las Cortes, Miquel Santaló, cuando en enero de 1933 declaraba el abandono político de su partido respeto de la actividad del Congreso, solo actuando en las votaciones básicas para el mantenimiento de la mayoría republicano-socialista. De este modo, toda la actividad política catalana se trasladó a Barcelona donde habría de debatirse el Estatuto Interior de Cataluña y las líneas maestras de la política del gobierno resultante de las elecciones del 20 de noviembre de 1932 donde ERC consiguió la mayoría absoluta de 56 escaños sobre los 85 de la cámara ${ }^{12}$. Un hecho que sumado a la duplicidad de actas de diputado en Barcelona y Madrid por parte de diversos parlamentarios catalanes, provocaría múltiples interpelaciones en las Cortes pidiendo la incompatibilidad y hasta la expulsión de los diputados catalanes. Y es que según algunos diputados a Cortes, si Cataluña tenía un Parlamento propio que excluía de sus decisiones al resto de los españoles, los diputados catalanes no podían pretender decidir sobre las políticas del resto del Estado.

Así, ya desde la sesión inaugural, los debates mantuvieron una constante discusión sobre la relación entre los partidos y la política catalana con la general española. La inexacta definición nacionalista de las principales fuerzas, ERC y la Lliga, que no se definían sino con los calificativos de nacionalista federalista o catalanista, situaban de manera constante en el debate parlamentario el interrogante de las relaciones con los gobiernos republicanos y de manera más genérica el papel a desarrollar por Cataluña en el seno de la República. Así, si todo el proceso republicano y autonómico ya provenía de los pactos de San Sebastián entre los partidos catalanes y españoles opositores a la monarquia, ahora era necesario redefinir cual era el papel de Cataluña en España.

De esta manera cuando el 14 de diciembre de 1932 Francesc Macià, presidente de la Generalitat hasta ese momento de manera provisional, abría las sesiones del Parlamento con un discurso lleno de referencias históricas a las luchas pasadas, lo hacía justificando el porque de la renuncia a la República Catalana del 14 de abril de 1931:

11 Dos visiones contrapuestas del hecho catalán y de su relación con la política general española en Fernández Almagro, M.: Catalanismo y República Española, Madrid, Espasa-Calpe, 1932. Totalmente crítico con el catalanismo, Royo Villanova, A.: Un grito contra el Estatuto, Madrid, 1932 y Treinta años de política antiespañola, Valladolid, 1940.

12 La correlación de los escaños fue la siguiente: ERC 56; Lliga 16; USC 5; PARA 4; PCR 1; PRDF 1; Unió Catalanista 1; UDC 1. Para la evolución electoral catalana, ver VILANOvA, M.: Atlas electoral de Catalunya durant la Segona República, Barcelona, Fundació Bofill-La Magrana, 1986. 


\begin{abstract}
«Quizás no sea este el momento ni el lugar, honorables Diputados, de hacer referencia a los motivos que me llevaron a pasar de la República Catalana, al restablecimiento de la Generalitat de Cataluña. Pero no quiero acabar este discurso sin dejar constancia de que razones de orden político y social me hicieron ver que seguir diciéndonos República Catalana era un peligro para la República Española y para nuestras libertades, dado el curso que tomaban los hechos de carácter social en toda España y lo poco despierto que se encontraba la conciencia colectiva de los otros pueblos peninsulares, para seguirnos en el camino federal, al cual, y desde el primer momento, queríamos llevarlos todos»13.
\end{abstract}

Con estas palabras, Macià, líder de ERC pero a la postre también fundador el 1922 del partido independentista Estat Català, planteaba la necesidad de seguir al lado de la naciente República Española negando cualquier proyecto separatista. Hecho que como he señalado provocó una cierta polémica que derivó en la publicación de obras donde se preguntaba: ¿Ha traicionado Macià? ${ }^{14}$ Al mismo tiempo que se hacía referencia a la posición de liderazgo republicano de Cataluña en el conjunto español, era necesario reforzar la República y «transformar» en republicanos, demócratas y federalistas a los demás pueblos de España ${ }^{15}$. Este planeamiento, heredero de los constantes proyectos de transformación de España planteados desde Barcelona a lo largo del XIX y XX, suponía por un lado la supeditación de la política catalana a la española, ya que era necesario esperar a convencer a los restantes territorios de unos postulados que en gran mediada nunca habían defendido, pero desde otro punto de vista se entrelazaban con lo que un observador español filocatalanista como Ángel Ossorio y Gallardo sentenciara pocos años después hablando del 6 de octubre de 1934 : «yo siempre he creído que en Cataluña no son separatistas ni siquiera los que lo dicen» ${ }^{16}$. Esta observación real si exceptuamos a los grupos del nacionalismo radical minoritario como por ejemplo la versión catalana del Sinn Féin irlandés, Nosaltres Sols! o los sectores de Estat Català integrados en ERC, seria el nexo común de la política catalana de los treinta. Lo que desde la mayoría de sectores conservadores de Madrid se calificó siempre de separatismo, no fue nada más que una política nacionalista pero sin ninguna intención de derivar en proyectos separatistas, sino todo el contrario, un proyecto de transformación de España y de consolidación de un espacio político propio extre-

13 Traducción del original en catalán, Diari de Sessions del Parlament de Catalunya, 14-XII1932, p. 62.

14 Miravitlles, J.: Ha trä̈t Macià, Barcelona, 1932.

15 Para la constante voluntad catalana de transformar España, en el caso del siglo XIX, ver RiQuer, B.: Identitats contemporànies: Catalunya i Espanya, Vic, Eumo Editorial, 2000 (también en versión castellana). Para el siglo XX es muy interesante la obra colectiva, Federalismo y Estado de las autonomías, Barcelona, Planeta, 1988.

16 Citado en carta de Ossorio a Jesús Lafuente, en Zambrana Moral, P.: El epistolario jurídico y político andaluz de Ángel Ossorio y Gallardo (1927-1935), Barcelona, Universidad de Málaga, 1997, p. 127. 
mamente vinculado a la política española. De lo que se trataba, y en esto insistieron de manera continuada los principales ideólogos del catalanismo, como el historiador y político Antoni Rovira i Virgili y los miembros de la Minoría Catalana en las Cortes Constituyentes, era de transformar la Península Ibérica en un estado federal con cuatro grandes naciones:

«En la Península no hay cuarenta y nueve personalidades de pueblos. No hay tampoco catorce y quince. Hay, cuatro personalidades, cuatro pueblos con carácter propio, cuatro naciones. Una nación al oeste, que es Galicia; otra en medio, que es Castilla; otra al norte, que es el País Vasco; otra al este, que es Cataluña, la Cataluña mayor, formada por todas las tierras donde es hablada la lengua única de los catalanes» ${ }^{17}$.

En otro sentido, algunos como el diputado a Cortes por la Lliga, Joan Estelrich, defendía una extensión de las autonomías al resto de territorios españoles para poder consolidar el Estatuto catalán, consiguiendo una situación donde se rompiera el desequilibrio entre el Estado central y Cataluña, para pasar a una relación multilateral de diferentes entes autónomos con el central ${ }^{18}$.

De esta manera, en la continuación de la primera sesión del Parlamento autónomo, una vez Macià fue votado como Presidente por los diputados, el vicepresidente del gobierno, Joan Lluhí i Vallescà, ampliaba los puntos de conexión imprescindibles con la política republicana según Esquerra:

«Pero no habrá suficiente con implantar bien el Estatuto y de haber demostrado que su implantación no perjudica el resto de España, es necesario, todavía, una condición esencialísima: la permanencia y la consolidación de la República en su mismo sentido liberal, democrático, y izquierdoso que la hizo nacer y la ha mantenido hasta ahora. (...) el Estatuto de Cataluña (...), en cuanto a su futura ampliación, tiene su suerte ligada a la de la República.»

No obstante, a estas palabras aun ampliadas con una declaración de fidelidad a la República, Lluhí les adjuntaba una especificación del valor de esta:

«En nuestra política de lealtad con el Gobierno de la República, tenemos la plena convicción, la absoluta seguridad, de obtener una lealtad recíproca del Gobierno de la República respeto a la autonomía de Cataluña. Es una garantía de esto la condición moral de los hombres que forman el Gobierno de la República»19.

17 Rovira i Virgili, A., Federació de nacionalitats, «La Humanitat», (Barcelona) 22-XII-1935. Este es un ejemplo de los múltiples artículos que en este sentido escribió a lo largo de su trayectoria, y especialmente en la década de los treinta el historiador tarraconense afiliado a ERC. Para una visión amplia de sus textos, ver la obra Antoni Rovira $i$ Virgili $i$ la qüestió nacional. Textos polítics 1913-1947, Barcelona, Generalitat de Catalunya, 1994. Y aun del mismo Rovira i VIRGILI, A., Resum d'història del catalanisme, Barcelona, Barcino, 1936. Sobre el movimiento pancatalanista ver mi obra: La nació imaginada. Els fonaments dels països catalans (1931-1939), Catarroja, AFERS, 2006.

18 ESTELRICH, J.: L'autonomia en perill. Barcelona, Llibreria Catalonia, 1932, p. 61.

19 Diari de Sessions del Parlament de Catalunya, 20-XII-1932, p. 74. 
Por lo tanto, con estas palabras se iniciaba la vinculación: AutonomíaRepública-Izquierda, que tantos problemas conllevaría para la consolidación del régimen democrático. Desde Cataluña no había otra República que la de izquierdas, las fuerzas del gobierno autonómico no contemplaban otra posibilidad, hecho que dejaba en el aire los escenarios futuros delante de un ascenso de las derechas españolas al poder. Por lo tanto, la autonomía de Cataluña se cimentaba en los valores «originarios» de la República: la tendencia izquierdista. Una posición que el Vicepresidente del gobierno, Joan Lluhí i Vallescà, hubo de reiterar minutos después de la intervención del jefe de la Minoría de la Lliga Regionalista que apreciaba ante el Parlamento:

«(...) nosotros afirmamos resolutamente y decididamente, también nuestro sentido de lealtad a la República, pero no con un Gobierno determinado ni con una ideología determinada ni con una matización determinada, que nosotros creemos que estas afirmaciones de lealtad, por encima de todo si incluyen un sentido de lealtad de Cataluña, han de ser de una manera general, independendientemente de que haya tal o cual Gobierno, tal o cuales hombres, o cuales principios predominantes» ${ }^{20}$.

La intervención del jefe de la Minoría regionalista, Lluís Duran i Ventosa, situaba el partido dominante del conservadurismo catalanista dentro de la República, pero con su tradicional accidentalismo. Cabe recordar que no seria hasta finales del año siguiente que la Lliga iniciaría un proceso de reconversión para adaptarse a la nueva situación política de masas (Asamblea de 1933, que derivó en un cambio de nombre: Lliga Catalana). No obstante, lo importante era la apreciación de Duran, que hacía prever la posible utilización de la Lliga de los cambios de gobierno de Madrid en clave interna catalana. Era evidente que durante las discusiones del Estatuto en las Cortes, la Lliga no podía oponerse a los diputados de ERC dilapidando el prestigio del catalanismo conservador, aunque las diatribas entre Cambó y el diputado Joan Estelrich en este sentido fueran permanentes. Pero una vez el Estatuto estuvo aprobado, y llevado a Cataluña por un partido nuevo como ERC y no por un Cambó que se creía injustamente abandonado por la opinión pública catalana, no quedaban muchas salidas para intentar recuperar el dominio político del país. Con un Parlamento autónomo dominado por Esquerra, de la misma manera que el resto de las instituciones, desde los ayuntamientos a la representación en Madrid, la Lliga iniciaba su apuesta por las alianzas externas. Del mismo modo, como el partido en el poder autonómico circunscribía su lealtad a la República al mantenimiento del gobierno de izquierdas en el que siempre hubo como mínimo un ministro catalán, y en el cual a partir de junio de 1933 participaría directamente con hombres como Lluís Companys o Carles Pi i Sunyer ${ }^{21}$.

20 Diari de Sessions del Parlament de Catalunya, 20-XII-1932, p. 82.

21 Para la participación de los diputados catalanes en las Cortes Constituyentes ver mi tesina de doctorado, GonzÁlez i Vilalta, A.: Els diputats de Catalunya a les Corts Constituents (19311933), Barcelona, Publicacions de l'Abadia de Montserrat, 2006. 
Pero volvamos a la sesión del Parlamento catalán del 20 de diciembre de 1932, cuando Lluhí i Vallescà respondía a la apreciación de la Lliga:

«V .S. también hablaba de lealtad al Gobierno. Y decía que era mejor que la lealtad a la República, que VV. SS. comparten, y yo me felicito por esto. Lealtad al Gobierno, id con cuidado, decía el señor Ventosa; en el sentido que solo se limita al actual Gobierno. Yo, respeto de este particular, también me he expresado de una manera precisa, y he dicho que estábamos plenamente seguros que nuestra lealtad a la República tendría la contrapartida natural de lealtad de la República a la autonomía. (...) Ahora bien: ¿Cómo puedo hacerme fiador de esta lealtad reciproca con otro gobierno? No me arriesgaría a firmarlo; y todavía llego a más: sin dejar de ser en ningún caso republicano, y lo mismo creo que pasaría con los restantes compañeros, (...) podría ser perfectamente que nos pusiéramos de frente, según el tono que tuviera la República» ${ }^{22}$.

Con estos discursos las dos principales fuerzas parlamentarias catalanas explanaban desde la más alta tribuna de Cataluña sus respectivas políticas en relación a los gobiernos republicanos. Desde una posición, en el fondo no tan distante en los planteamientos pero si en las formas, los dos partidos planteaban unas posiciones en teoría enfrentadas. Desde la Esquerra, y respondiendo a la increíble amalgama de tendencias del partido (desde independentistas a republicanos federalistas o izquierdistas diversos) la República era el marco donde Cataluña había de desarrollar su autonomía, pero no podía ser otro Estado que no fuera el de izquierdas. En primer lugar porque ERC se definía como formación de izquierdas e incluso socializante, pero también porque habían sido las izquierdas, Azaña y el PSOE, y no precisamente sin oposición interna, los que habían permitido la aprobación del Estatuto de Autonomía, que aunque muy recortado respeto al texto votado por el pueblo catalán en agosto de 1931 era el primer documento que reconocía la identidad catalana en más de dos siglos. Además, y aquí entraba en juego la subsidiariedad de la política catalana respeto a la española, pero en cierta medida en sentido inverso, los miembros de ERC sabían que sin ellos la República Española concebida desde la izquierda, y seguramente la idea misma de República democrática no podía mantenerse en pie. Al mismo tiempo, como decían las palabras de Macià, la autonomía catalana no era concebible sin el mantenimiento de la República Española. Por lo tanto, esta situación de simbiosis, es decir la necesidad mutua entre ambos sectores, empujó a unos a aceptar el Estatuto como el mal menor para conservar la Cataluña republicana de izquierdas a su lado, mientras que desde Barcelona esta realidad provocaba una constante táctica de duda sobre la legitimidad del marco político autónomo. Y es que la autonomía catalana era indisociable de los equilibrios y alianzas en las Cortes republicanas. Era evidente que la Lliga Regionalista no podía sino aceptar el régimen republicano, pero a su vez

22 Diari de Sessions del Parlament de Catalunya, 20-XII-1932, p. 86. 
también era fácil de prever que ante la exclusión de la que fue objeto de los puestos de responsabilidad en el primer bienio, acudiera a la política española para intentar recuperar cuotas de poder en Cataluña. Si no podía cuestionar la política autonómica desde dentro lo haría desde fuera. Así se hacía evidente que tanto unos como otros, ERC y Lliga, utilizarían la posibilidad del doble marco político instaurado por la autonomía para cubrir en Madrid sus propias debilidades y derrotas. La duplicidad de marcos políticos permitiría trasladar los éxitos propios o ajenos conseguidos en Madrid, como fórmula de alterar la correlación de fuerzas en Barcelona.

Por eso Duran i Ventosa situaba el discurso regionalista y el debate con Lluhí ante la posibilidad de un gobierno republicano de derechas. Situación que para los regionalistas habría de interpretarse como una victoria de la Lliga, de la misma manera que Esquerra se vinculaba a las fuerzas lideradas por Azaña. Consideraciones con las que se hacía patente la constante presión política sobre un marco autonómico, para nada consolidado y libre de vaivenes políticos.

\section{LAS DERECHAS EN EL PODER: SESIÓN DEL 28 DE NOVIEMBRE DE 1933}

En este contexto, una vez las Cortes Constituyentes estuvieron agotadas, la convocatoria de elecciones para el 19 de noviembre de 1933 abría la posibilidad a un nuevo sistema de mayorías en las Cortes republicanas. En Cataluña si hasta ese momento, ERC había llevado el peso de la Minoría Catalana en las Constituyentes, la Lliga esperaba infligir por fin la primera derrota al partido que «le había robado el Estatuto». Después de cuatro derrotas, la Lliga utilizó una constante propaganda de desprestigio de los hombres de Esquerra criticando su mala gestión, su radicalidad en sectores como el agrícola, las conexiones con el anarcosindicalismo y sus ataques a la fe católica para conseguir poner en pie a múltiples sectores de la sociedad catalana. A su vez el préstamo de votos anarquistas conseguido por el partido de Macià en las elecciones a Cortes Constituyentes del 28 de junio de 1931, había sido rescindido de manera total después de acabarse la luna de miel entre la Generalitat y la CNT con diversos levantamientos armados en el Alto Llobregat o en Súria. Esta situación, sumada al normal desgaste de las fuerzas que habían aprobado el Estatuto, verdadero caballo de batalla de las derechas españolas, la Reforma Agraria y una legislación laica que prohibió entre otras cuestiones la enseñanza religiosa, y juntamente con la desunión de las candidaturas de izquierdas llevó a la victoria del centro-derecha. Las nuevas Cortes, a diferencia de las anteriores tendrían como minoría con mayor número de diputados a la CEDA con 115 y la radical con 100 (por 59 del PSOE y 10 de Izquierda Republicana) ${ }^{23}$. En lo que respeta

23 En las Cortes Constituyentes el PSOE obtuvo 113 escaños, el Partido Radical 88, el PRRS 52 y 30 de Acción Republicana, antecesora de Izquierda Republicana y el Partido Radical-Socialista. 
a los resultados en Cataluña, la apabullante victoria de ERC en 1931, no se había repetido, pero a diferencia del resto de España los escaños obtenidos por la derecha, en este caso la Lliga, no habían sido tan espectaculares. Ciertamente la Lliga obtuvo un gran vuelco de diputados, ya que pasó de 4 a 27 , pero ERC aunque acusó una acentuada perdida de escaños se quedó en 17 de los 30 que tenía. Y aun si sumamos los 3 de la USC, los 3 de los federales del PRDF, y los diputados de Acción Republicana y del PSOE, los resultados daban casi un empate técnico entre izquierdas y derechas ${ }^{24}$.

Por lo tanto Cataluña se mantuvo en gran medida fuera de la corriente general que produjo una debacle total de los partidos de izquierdas para dar una victoria amplísima al centro-derecha. No obstante, la Lliga no podía desaprovechar aquella ocasión para trasladar los resultados de las elecciones a Cortes al Parlamento catalán intentando deslegitimar su composición. Así con ese objetivo el 28 de noviembre de 1933 su minoría presentaba ante la cámara una interpelación sobre «las consecuencias políticas de las últimas elecciones legislativas».

En una larga discusión que a continuación analizaré, la Lliga reclamaría elecciones anticipadas al Parlamento de Cataluña como consecuencia de los resultados de los comicios a Cortes. Argumentando que los electores catalanes habían perdido la confianza en Esquerra, para depositarla en la Lliga, el catalanismo conservador anunciaba la imposibilidad del partido de Macià y Companys de negociar con un gobierno republicano dominado por las derechas con las que se habían declarado incompatibles en repetidas ocasiones. Comentando esta circunstancia el cronista barcelonés de «ABC» escribía:

«Total, que por un lado se nos ofrece una reproducción en miniatura de las Cortes Constituyentes de la República, negándose a oír los latidos de la opinión, y por otro se nos presenta la Lliga Catalana queriendo mangonear en el Gobierno de Cataluña como verdaderos depositarios o guardadores del espíritu autonomista, mientras pretenden también entrar con aire conciliador y de arreglacuestiones en el Gobierno de la República» 25 .

Así, Duran i Ventosa decía en los primeros compases de su intervención:

«No es posible señores diputados, que el Parlamento de Cataluña se reúna en el día de hoy, y plagiando la frase de Fray Luis de León, reprendiendo sus tareas, diga sencillamente «decíamos ayer.» No; no es posible (...) porque ha pasado algo de muy grave en Cataluña; algo que tiene una inmensa trascendencia en nuestra vida política. No es solamente que haya desaparecido del todo, que haya caído

\footnotetext{
Para esta evolución ver VARela, S.: Partidos y parlamento en la II República Española, Madrid, Editorial Ariel, 1976, p. 68-72.

24 Cabe recordar que en tres de las cinco circunscripciones catalanas, entre ellas las dos más importantes, Barcelona ciudad y provincia, ERC ganó los comicios. La Lliga por su parte solo obtuvo mejores resultados en Lleida y Tarragona.

25 Pedro Pujol, Votamos por el pobre Sr. Santaló, «ABC», 29-XI-1933
} 
la hegemonía de las fuerzas que representan el Gobierno actual de la Generalitat de Cataluña (...).»

Seguía Duran insistiendo en la desconfianza mostrada por el cuerpo electoral catalán en las políticas y la actuación del gobierno autónomo presidido por Francesc Macià, planteamiento a partir del cual se derivaba según la visión de la Lliga una más que discutible apreciación sobre la autonomía del Parlamento catalán:

«Es evidente, que una mayoría inmensa del Cuerpo electoral de Cataluña os ha desautorizado, es evidente que, aplicado el resultado de estas elecciones a unas elecciones al Parlamento de Cataluña, vosotros estarías en una Minoría y nosotros, con otros elementos, probablemente constituiríamos una Mayoría. En estas condiciones, ¿tenéis autoridad suficiente para seguir gobernando? ¿Tenéis autoridad suficiente para seguir desarrollando vuestra obra? O bien se os impone la sustitución o la rectificación de vuestra conducta» ${ }^{26}$.

De este modo y con gran claridad la Lliga ponía sobre la mesa la necesidad, siempre según sus criterios, de reformar el gobierno, sus políticas y llegar en último pero inevitable lugar a la disolución del Parlamento y la convocatoria de elecciones para refrendar el resultado del 19 de noviembre. Por lo tanto, los resultados obtenidos en unos comicios generales a Cortes, habían de condicionar de manera absoluta la vida de la cámara catalana. Se definía como imprescindible un paralelismo exacto entre las mayorías en Barcelona y Madrid, porque si desde este punto de vista la victoria de la Lliga cuestionaba la legitimidad del gobierno de ERC, también cabía valorar los resultados desde otro prisma: «(...) igualmente grave, es el de la autoridad con la que podéis tener la representación de Cataluña ante el Gobierno de Madrid en estos momentos críticos de nuestra vida autónoma» ${ }^{27}$.

Con estos argumentos la Lliga disparaba de pleno en la línea de flotación de la autonomía catalana: la legitimidad propia de su gobierno y parlamento indistintamente de las mayorías en Madrid. Y es que se ponían en tela de juicio las elecciones del 20 de noviembre de 1932 que configuraron el Parlamento autónomo, y que a la postre serían las únicas en todo el período 1932-1939. Se pedía la supresión del curso normal de la vida parlamentaria, es decir los cuatro años de legislatura, para condicionarlos a los resultados generales españoles una vez estos eran favorables o contrarios respectivamente a las fuerzas catalanas en el poder y la oposición. Se pedía que ERC rectificara sus políticas para ir cediendo y traspasando paulatinamente el poder a la Lliga, al mismo tiempo que en este tránsito incorporara al gobierno a todas las fuerzas presentes en el Parlamento autónomo.

26 Diari de Sessions del Parlament de Catalunya, 28-XI-1933, p. 2697.

27 Ibíd. p. 2698. 
Ante estos planteamientos, la cuestión de las relaciones con el gabinete republicano se situaba en una posición de gran importancia, ya que en unos momentos en que todavía se estaban realizando los traspasos de competencias, etc., las enormes diferencias entre los gobiernos central y autonómico podían suponer un gran obstáculo a la consolidación de ese proceso.

Ante esta argumentación el Conseller primero, Miquel Santaló, rechazaba las consecuencias derivadas por los catalanistas conservadores y negaba la total subordinación de la política catalana respeto a la española:

«Son unas elecciones generales convocadas por el Gobierno de la República, elecciones generales para constituir un Parlamento de la República, un Parlamento que ha de discutir las cuestiones generales de la República, entre los cuales, naturalmente, hay algunas que afectan a Cataluña»28;

Continuaba afirmando Santaló que en contra de lo que argumentaba la Lliga, los catalanistas de izquierda del gobierno habían conseguido a partir del 14 de abril de 1931, mucho más que no los regionalistas conservadores en las tres décadas anteriores y ganado las elecciones del 19 de noviembre de 1933. Así, con esta discusión se mostraba de manera más que evidente la dificultad de consolidar un sistema político catalán que si bien había de vincularse inevitablemente con el general español, en el período republicano se situó como un apéndice subsidiario con características propias. De este modo, si era normal que los grandes debates políticos del estado se situaran en la agenda de los partidos catalanes, también era necesario tener en cuenta que no había ni un diputado del Parlamento catalán que fuera de alguna formación estatal.

Esta realidad la expresaba el diputado socialista, Manuel Serra i Moret, cuando decía:

«Es evidente que no vivimos aislados y que cuando va una ola hacía un lado o hacía otro, siempre que se hagan elecciones generales, esta ola repercutirá en Cataluña, no solamente por la Ley de los vasos comunicantes, sino porque es perfectamente explicable que mientras no haya fronteras políticas entre Cataluña y el resto de España, el movimiento general de España de una manera o otra habrá de reflejarse en Cataluña» ${ }^{29}$.

Continuando con su intervención Serra i Moret preguntaba a la Minoría de la Lliga si mantenían alguna alianza con las fuerzas que acababan de ganar. Y es que la introducción de los resultados de las elecciones a Cortes en el debate de la política parlamentaria catalana, podía suponer que la Lliga se erigiera en el referente de los partidos de derechas españoles en Cataluña. Porque era lógico que Esquerra fuera el aliado catalán de Acción Republicana y después de IR

28 Diari de Sessions..., p. 2700.

29 Diari de sessions..., p. 2704. 
sin perder su connotación nacionalista, pero por su parte la Lliga no se podía presentar ante nadie como aliado de unas fuerzas que como la CEDA se caracterizaban entre otros factores por su feroz anticatalanismo. Por lo tanto, había de presentarse como el partido idóneo para negociar con el poder central, por su proximidad ideológica en lo social pero no en lo territorial.

No obstante, en esta discusión lo que se ponía en juego era una doble lealtad, primero la del gobierno de la Generalitat para con una República gobernada por las derechas, y en segundo termino la fidelidad de la Lliga Catalana al sistema autonómico. Es decir: o intentar ganar la confianza de la población catalana en el Parlamento autónomo y en su ámbito político, o recurrir a la política española como arma para obtener el poder que las urnas no le habían concedido, como haría en 1935 en plena suspensión del Estatuto. Porque ni en esto estaban de acuerdo los diputados y principales portavoces periodísticos de los dos partidos. Así, si La Veu de Catalunya, portavoz de la Lliga, se vanagloriaba del mejor resultado del partido en toda su historia en unas elecciones a Cortes y manifestaba que aquella era la victoria del catalanismo autentico: «Para evitar los errores que han producido el fracaso de Esquerra, no nos hace falta rectificar nada. Hay suficiente con insistir en la doctrina y en la conducta de siempre del catalanismo histórico» ${ }^{30}$. Por su parte, el portavoz de ERC proclamaba que la victoria electoral era suya, imitando a sus oponentes en apropiarse del catalanismo:

«Las cifras de los escrutinios demuestran plenamente que Cataluña es catalanísima y republicanisima, que es un pueblo de espíritu nacional y de espíritu liberal. Esquerra Republicana, exponente principal del izquierdismo y del catalanismo en este período de nuestra historia política, sigue siendo el que ha aunado más sufragios (...). Nuestro pueblo, en medio de una riada de derechas tan formidable como pocas veces se ha visto, se ha mantenido con coraje en su lugar $(\ldots) »^{31}$.

Recuperando la discusión en el Parlamento, Lluhí i Vallescà intentaba lanzar un grito de en defensa de la diferencia de marcos políticos, argumentando que desde un estricto sentido autonomista, los resultados de las elecciones reflejaban la opinión de los electores catalanes en cuanto a la orientación de la República, pero no de la Cataluña autónoma. Además insistía en una línea de crítica similar a la de la Lliga meses antes: «(...) creer que de estas elecciones se puede deducir consecuencias porque aquí en Cataluña haya de haber un gobierno que guste a Madrid, un Gobierno que se considere más autorizado en Madrid!»32 Según el diputado de Esquerra, lo que tenía que hacer el principal partido de la oposición era mantener una estricta colaboración en el campo autonómico con el partido de gobierno, evitando intentar confundir la política

30 Visca Catalunya!, «La Veu de Catalunya», 22-XI-1933.

31 A. Rovira i Virgili, Editorial, «La Humanitat», 21-XI-1933.

32 Diari de sessions..., p. 2707. 
catalana con la española con finalidades totalmente opuestas a la arquitectura institucional creada por el Estatuto y la Constitución. En esta dirección la cámara aprobaba una declaración que sentenciaba la firme voluntad del Parlamento catalán de continuar en la aplicación del Estatuto de Autonomía. Esta declaración, rechazada por la minoría de la Lliga, serviría a los periódicos de Esquerra para proclamar que «La Lliga, [está] contra el Estatuto»33, en un nuevo episodio de la lucha por apropiarse de la patente del catalanismo que a largo de los treinta enfrentó a las dos formaciones.

No obstante, desde otro punto de vista, la izquierda catalanista empezaba por aquellos días a difundir la idea de una Cataluña «baluarte de la República». Dos planteamientos, el de la imposición de los cambios españoles sobre la política catalana, y el de la construcción de la imagen de la retaguardia de la República de izquierdas, que tuvo en el único diputado de la UDC, Pau Romeva, una interesante crítica. Desde una posición de nacionalista radical, Romeva exponía lo que desde ciertos sectores del catalanismo se había repetido a lo largo del bienio 1931-1933: la necesidad de la unión de todos los partidos catalanistas ante el gobierno republicano. Demanda que fracasó en la campaña electoral de junio de 1931, y que evidentemente volvería a fracasar en 1932 y 1933. Y es que la Cataluña de los años treinta, como España o Europa no estaba en unos momentos demasiado favorables a la unión interclasista, sino más bien al contrario. Era demasiado tarde para repetir una nueva Solidaridad Catalana como la de 1907.

En ese momento en plena II República, los partidos catalanes, particularmente ERC y la Lliga pero también otros como la USC, pretendían conseguir sus objetivos a través de la vinculación a las formaciones estatales. Esquerra con un poder real como era el de la Generalitat, y la Lliga con otro que era la posibilidad de provocar la inestabilidad de la autonomía. De todas maneras, la apreciación de Romeva no carecía de interés, y más cuando este diputado se distinguiría durante toda la legislatura por la coherencia de su discurso. Así, el demócrata cristiano decía:

«Yo no tengo preocupaciones en relación a las mayores o menores facilidades que puede obtener Cataluña de los Gobiernos de Madrid por relación a la filiación política de la tendencia dominante, porque en realidad siempre he entendido que Cataluña, delante de España, no encontrará más que resistencias, resistencias que se manifestaran según la conveniencia y la posición táctica de cada momento, pero resistencias efectivas que nosotros siempre nos encontraremos con la necesidad de vencer $(\ldots) .{ }^{34}$

Una situación la discutida en el Parlamento catalán que tendría una réplica en las Cortes republicanas dos meses después. En aquella ocasión y después de

33 «La Humanitat», 29-XI-1933.

34 Diari de Sessions..., p. 2709. 
que el jefe de la Minoría de la Lliga, Joan Ventosa i Calvell, defendiera la aceptación de los resultados electorales y criticara la actitud revolucionaria del PSOE ante los posibles cambios en la legislación social, el representante de ERC acusaba las contradicciones de su adversario:

«Y dos palabras para terminar, al objeto de recoger unas manifestaciones del Diputado Sr. Ventosa, (...) ha querido glosar la necesidad de que el resultado del sufragio fuese siempre respetado. Es curiosa esta manifestación del jefe actual de la minoría de la Lliga Regionalista, hecha en el Parlamento de la República, olvidando cómo, al ver en Cataluña perdidas las últimas elecciones, han procedido en forma totalmente distinta» 35 .

\section{¿LA ACTUACIÓN CONFUSIONARIA DE LA GENERALITAT SEPARATISTA? SESIÓN DEL 1 DE OCTUBRE DE 1934}

A lo largo de 1934 la política española fue calentándose cada vez más. Mientras las izquierdas se reclamaban como las únicas y autenticas fuerzas republicanas, las Cortes dominadas por la CEDA y el Partido Agrario intentaban reformar a fondo las principales leyes del bienio azañista. Al mismo tiempo, la Cataluña dominada por las izquierdas catalanistas, único poder no dominado por las derechas, se erigía cada vez más en el referente político de los que se autodenominaban los «auténticos republicanos.» En aquellos momentos, después de la muerte de Francesc Macià el día de navidad de 1933, su sucesor, Lluís Companys, cuestionado por su «débil» nacionalismo había constituido un gobierno de unidad donde se incorporaron todas las fuerzas catalanistas de izquierdas, desde la escisión de Esquerra, el Partit Nacionalista Republicà d'Esquerra (PNRE), pasando por Acció Catalana Republicana y la USC.

Con esta situación, y una vez las elecciones municipales del 7 de enero de 1934 hubieron rectificado el rumbo del voto, devolviendo la hegemonía a ERC, la Lliga volvió a girar la mirada hacía Madrid para encontrar un balón de oxígeno con el que mantener sus posiciones. Una posición que se veía cuestionada desde una doble dirección: desde Cataluña porque ERC había recuperado el dominio electoral, y desde Madrid porque los principales partidos de derechas empezaron a mediados de 1934 a romper el pacto tácito que reservaba a la Lliga el espacio conservador en Cataluña. La CEDA con su Acció Popular Catalana, como ejemplo más importante inició el quebrantamiento del casi monopolio lligaire sobre los sectores conservadores, sobretodo de los agrícolas que veían como la Lliga no podía asegurar sus intereses.

Ante este panorama, y en el momento de perder el control del Institut Agrícola Català de Sant Isidre, agrupación de los propietarios agrícolas, la Lliga se lanzó a la aventura e instó al gobierno republicano a impugnar la Ley de

35 Diario de Sesiones de las Cortes, 7-II-1934, p. 965. 
Contratos de Cultivo aprobada por el Parlamento de Cataluña en abril de 1934. De nuevo la Lliga situaba la política española en el ojo del huracán de la catalana. Esto sumado al inestable equilibrio de fuerzas internas existente dentro de ERC, con un enfrentamiento entre las juventudes de Estat Català y los restantes sectores (a finales de 1933 ya se había escindido el PNRE), se resumía en una más que complicada situación política.

Con un constante enfrentamiento, cuanto menos dialéctico, entre el gobierno catalanista de izquierdas de Barcelona y el derechista de Madrid, con un frente abierto en el Tribunal de Garantías Constitucionales provocado por la Lliga que había abandonado el Parlamento catalán y con quien cada vez se acentuaban más las distancias (ERC abandonó por su parte las Cortes), y con un partido en el poder autónomo que no podía sino malvivir a sus tensiones internas. Con esta larga lista de problemas, el gobierno catalán liderado por Companys se lanzó también a la palestra española realizando una equivoca y errante política entre separatista y republicana izquierdista. En este contexto, entre constantes proclamas de lucha hasta la muerte en defensa de la autonomía y de los «auténticos» valores republicanos, y con una relación confusa con los sectores independentistas del gobierno liderados por Josep Dencàs y los hermanos Badia, el 1 de octubre de 1934, a solo cinco días de la proclamación del Estado Catalán dentro de la República Federal, y tres meses después de aprobar por segunda ocasión la ley de Contratos de Cultivo declarada inconstitucional, el Parlamento de Cataluña vivía una nueva discusión en gran parte vinculada a todas estas cuestiones.

Inició el debate, el jefe de la minoría lligaire acabada de reincorporar al Parlamento, Duran i Ventosa que después de acusar la falta de un programa político concreto del gobierno catalán, decía:

«Vivimos en este confusionismo porque, aquí i fuera de aquí, no se sabe bien cual es la orientación de la Generalitat de la Cataluña autónoma. Hay en determinados sectores una orientación separatista; hay en otros sectores una orientación diametralmente contraria a la orientación separatista» ${ }^{36}$.

Seguía el portavoz de la Lliga para explanar las consecuencias de esa actitud según su partido, que a parte de mal meter la confianza y la imagen de la Generalitat ante la opinión pública catalana y española, provocaba:

«(...) produce a su vez este confusionismo que está perjudicando en estos momentos de una manera tan grave y trascendental (...), las relaciones entre nuestra institución principal, la Generalitat de Cataluña, y el Gobierno de la República Española. (...) Lo que no es posible, desde el Gobierno, es aparentar que se es separatista según quien sea que gobierne la República española; no se puede admitir en un problema de esta trascendencia, en un problema de esta gravedad,

36 Diari de Sessions..., 1-X-1934, p. 4117. 
presentarse como separatista si en Madrid hay un Gobierno de derechas o no separatista si en Madrid hay un Gobierno de amigos» ${ }^{37}$.

A continuación cuestionaba también la vía emprendida por el gobierno Companys en desafiar al Tribunal de Garantías y no acatar su sentencia que declaraba ilegal la Ley de Cultivos, a la vez que reafirmaba la necesidad imperiosa de mantener una cordial relación con el gobierno republicano ya que la autonomía catalana se había de reafirmar fuera de Cataluña.

Respondería el mismo Companys, que a las críticas de Duran no negaba la dualidad de discursos: uno en Madrid y uno en Barcelona, pero lo defendía como una formula diversa para cada ámbito político acusando al diputado de la Lliga de realizar un discurso «españolista unitario». Todavía en un discurso lleno de referencias a la concepción del nacionalismo catalán de cada partido, Companys llegaba a decir: "Pero entiéndalo bien: desde el momento en que unos elementos de izquierda, de las fuerzas españolas, no respeten y no lleven los derechos de Cataluña, ya dejaran de ser amigos nuestros» ${ }^{38}$.

No obstante, la intervención más interesante del debate volvió a ser sin lugar a duda la de Pau Romeva, que aunque representara una ínfima porción de la población catalana, mantenía en su discurso una línea de puro nacionalismo, que en gran medida rompía con el confusionismo de ERC y la Lliga y dejaba entrever con claridad la autentica naturaleza de la discusión. Romeva explicaba con claridad:

«(...) quería decir que Cataluña, en tanto su libertad no sea totalmente reconocida, y en tanto su unión con los otros pueblos ibéricos no sea efecto de un pacto absolutamente libre, ha de considerarse una cosa al margen, y ha de resolver sus problemas y ha de mover su vida política con una independencia absoluta de la vida política española, porque cuando no se hace esto, se crea una situación que se ha sufrido en los tiempos de la Monarquía, y que se está sufriendo en los tiempos de la República. Y es que los partidos catalanes, los partidos catalanes más fuertes, viven siempre dependiendo de las vicisitudes de la vida política española, y entonces pasa que aquella pequeña ayuda (...), que cada partido catalán ha podido ir a buscar en los partidos españoles a favor de Cataluña, ha estado contrapesado con la división que ha creado dentro de Cataluña (...). Pero tengamos bien presente como una cosa inevitable, como una cosa con la que siempre se debe contar, que la actitud del Gobierno del Estado español, en relación a los problemas totales de la autonomía de Cataluña, siempre estará afectado por el signo político de ellos y por el signo político del Gobierno que haya en Cataluña (...)»39.

El discurso de Romeva, de gran interés para la cuestión que nos ocupa, incorporaría todavía una nueva consideración muy sugerente: «Mientras nosotros

37 Ibíd.

38 Diari de Sessions..., 1-X-1934, p. 4124.

39 Diari de Sessions..., 1-X-1934, p. 4125. 
queramos gobernar Cataluña, y, al mismo tiempo, intervenir en el Gobierno de España, seremos abogados de dos partes contrarias y neutralizaremos nuestra propia acción» ${ }^{40}$.

Romeva lanzaba un dardo venenoso directamente a la clave de todo el debate: el nacionalismo intervencionista. Según esta visión, compartida por los sectores minoritarios del nacionalismo y independentismo radical, la política de los partidos catalanes no podía basarse en una constante lucha interna a través de las alianzas con las formaciones estatales.

\section{LA AUTONOMÍA CATALANA ADMIRAdA POR TODA ESPAÑA. SESIÓN DEL 6 DE MAYO DE 1936}

Cinco días después del debate del primero de octubre, el Presidente de la Generalitat, Lluís Companys, proclamaba el Estado Catalán dentro de la República Federal Española. El acto, impregnado de múltiples connotaciones políticas diversas, tenía en las conexiones de la política catalana y española uno de los factores básicos. La evolución de la política española, como hemos visto en el debate posterior a los comicios del 19 de noviembre, había afectado rápidamente en Cataluña. Así, si desde ese momento la Cataluña dominada por Esquerra se transformó en el «bastión izquierdista» español, el 6 de octubre acentuaría su posición en la política general. Y es que el 6 de octubre catalán, lejos de ser una proclama independentista, era un acto de fe republicana española de izquierdas. Companys, cuestionado hasta la saciedad por las juventudes de Estat Català por su falta de pedigrí nacionalista, aprovechó la oportunidad de acabar con ese contrapeso interno, acrecentar su imagen de catalanista, al mismo tiempo que situaba Cataluña y su propia figura en el centro de la política española ${ }^{41}$.

Si en Madrid el gobierno republicano presidido por Lerroux daba cabida en sus consejos de ministros a los miembros de la CEDA, supuestos fascistas según la propaganda de las izquierdas, dispuestos a desmantelar la Republica, la Cataluña de Esquerra se lanzaba a salvar los valores republicanos españoles.

Evidentemente que una parte de los factores decisivos fueran el antiautonomismo del principal partido de las Cortes, y que a partir de su entrada en el gobierno, el Estatuto se creyera en peligro, pero la subsidiariedad de la política catalana respeto de la española hacía que Cataluña tuviera que intentar salvar la España de izquierdas. Por lo tanto, de manera contraria a la que se ha presentado en muchas ocasiones, el 6 de octubre catalán no fue un golpe sobera-

40 Diari de Sessions..., 1-X-1934, p. 4125.

41 Sobre la proyección de Companys ante la opinión pública española es muy interesante la obra de Gómez Hidalgo, F.: Cataluña-Companys, Madrid, 1935. Esta obra con prólogo de Azorín, se realizó en el contexto del juicio al que fue sometido Companys y su gobierno ante el Tribunal de Garantías Constitucionales en mayo de 1935. 
nista, aunque es cierto que para unos cuantos sí, sino un golpe autonomista izquierdista de ambición española. No se explica sino que Companys quisiera instalar la capital de la propuesta República Federal Española en Barcelona. Aunque también debe interpretarse como un intento de atraer a la capital catalana la centralidad de la política española, intentando por enésima vez construir España desde Cataluña como preconizarían en aquellos momentos autores como Gabriel Alomar.

Con todo esto, el 6 de octubre en Barcelona fue un sonoro fracaso, acaso incitado por Companys que no dio órdenes de atacar a sus fuerzas, y que condujo a la prisión al gobierno autónomo y a gran parte de las corporaciones municipales e instituciones de Cataluña. Además en unas más que duras discusiones en las Cortes generales donde se pidió la derogación, el gobierno de centroderecha de Lerroux suspendió el Estatuto tras solo dos años de aplicación con la Ley del 2 de enero de 1935.

Con este contexto, y tras un año 1935 en que se había sucedido la condena de Companys a treinta años de presidio, constantes casos de corrupción, crisis del gobierno republicano y constantes rumores de convocatoria de elecciones, el 16 de febrero se celebraban unos comicios de gran trascendencia. En ellos los resultados de Cataluña, de manera paralela a los españoles, daban como vencedor al Front d'Esquerres de Catalunya, hecho que implicó de manera inmediata la liberación del gobierno autónomo y la restauración del Estatuto.

Una vez retomada la política catalana como estaba el 5 de octubre, el Parlamento autónomo celebraba una sesión monográfica sobre los hechos del 6 de octubre. Un debate que volvería a poner sobre la mesa diversas preguntas: ¿porque Companys proclamó el Estado Catalán dentro de España y no la República Catalana? ¿Había de seguir interviniendo Cataluña en la política española? ¿Cual era la visión del Estatuto en el conjunto de España?

El primer interrogante, planteado por el diputado radical independiente Simó i Bofarull era contestado por el mismo presidente Lluís Companys, que recordando los objetivos de defensa de la República y el Estatuto de su proclama del 6 de octubre decía:

«Había en el ambiente de Cataluña y de España el recelo que pudiesen ser llamados al Poder elementos políticos que habían ido a las elecciones de una manera confusionaria y que defendían a cara descubierta, desde sus periódicos y sus autoridades responsables, la estructuración fascista del Estado. Cataluña ha de intervenir — según mi juicio- dentro de la política general española de una manera muy discreta. Cataluña ha de tener cuenta en conservar y respetar y hacer respetar sus instituciones autónomas $(\ldots) »^{42}$.

Momentos después, Companys explicaba que hasta el mismo Josep Dencàs, líder de Estat Català, había aceptado que en el contexto del 6 de octubre no

42 Diari de Sessions del Parlament de Catalunya, 5-V-1936, p. 4315. 
podía sino proclamar-se el Estado Catalán dentro de la República Federal Española. Y es que se trataba de una acción española, solidaria con toda la República y coordinada con la rebelión de Asturias, o cuanto menos con la actitud de rebelión del PSOE en el conjunto del estado ${ }^{43}$.

Como el 14 de abril de 1931, descontando la actuación de Macià, Cataluña se había situado de nuevo en la vanguardia democrática, izquierdista, autonomista y resumiendo según la visión de Companys en el liderazgo del republicanismo español. Por eso el Presidente de la Generalitat decía a los diputados del Parlamento autónomo:

«De manera que Cataluña, por su sensibilidad republicana y por su amor a las instituciones autónomas que están dentro de la Constitución, y, por lo tanto, defendiéndolas defiende la Constitución, aúna su esfuerzo a la protesta unánime, no ya de las izquierdas, sino de todos los partidos auténticamente republicanos de España, y esto lleva por el proceso y por todo lo sucedido a un estado sentimental y reacciona la gente, y Cataluña toma un sentido de influencia, de irradiación, y las instituciones autónomas son queridas fuera de Cataluña de manera que no se habría conseguido ni con mil discursos ni con cinco años de propaganda (...) ¿creéis que haya nadie de los vencedores del 16 de febrero que nos regatee la mas pequeña cosa de las instituciones autónomas tal como estaban establecidas» ${ }^{44}$.

Companys resituaba la cuestión catalana en el centro de la política española, como ya había hecho ante el Tribunal de Garantías Constitucionales, porqué era en ese contexto donde según su visión se debía desarrollar: una Cataluña de izquierdas, cada vez más en conexión con los restantes pueblos españoles y que proseguidamente consiguiera la transformación de España hacía un estado federal donde el supuesto espíritu catalán predominara sobre el castellano ${ }^{45}$. Una visión que se basaba en la posición que ya habían manifestado otros políticos catalanes convencidos de la vocación española de la política catalana, como el radical-socialista y ministro republicano (y expulsado de ERC en 1932), Marcel.lí Domingo cuando en los últimos tiempos de la dictadura decía:

«El problema de Cataluña, integrando Cataluña al Estado español, es inevitablemente un problema español. Podrá Cataluña, afirmar su personalidad, ascender a ser, como Irlanda, un problema europeo; pero no dejará por esto de ser un problema español (...). Yo creo, en resumen, que la pregunta: «Donde va Cataluña?» habría de contestarse así: Cataluña va a colaborar con los que se pro-

43 Para este cuestión ver, VidARTE, J. S.:El Bienio Negro y la insurrección de Astúrias, Barcelona, 1978, pp. 222-223.

44 Diari de Sessions del Parlament de Catalunya, 5-V-1936, p. 4320.

45 Para las intervenciones de Lluís Companys en el juicio que contra él y su gobierno se celebró a finales de mayo de 1935 en el Tribunal de Garantías, ver PRATS, A.: El gobierno de la Generalidad en el banquillo. Barcelona octubre 1934, Madrid mayo 1935, Barcelona, 1935; también editado por el periódico «La Publicitat»: El govern de la Generalitat davant el Tribunal de Garanties, Barcelona, Edicions de La Publicitat, 1935. Está próximo a publicarse mi trabajo junto a G. Bou Garriga: L'Epistolari Lluis Companys - Ángel Ossorio y Gallardo (1934-1936). O les conseqüenciès del 6 d'octubre. 
pongan dar a España un régimen de libertad y de democracia, por lo tanto, una República. Solo en una República que acate las expresiones del sufragio podrá Cataluña, con su plenitud de soberanía que el sufragio le atorgué, en un plebiscito, decidir sobre su suerte» ${ }^{46}$.

A partir de la aceptación de estas consideraciones como elementos axiomáticos de la relación entre Cataluña y el Estado Español, la política catalana se debía a la defensa del marco legal que le había concedido el derecho a decidir en plebiscito el Estatuto y que posteriormente había legitimado la instauración de la Autonomía.

Unos argumentos que se habían visto reafirmados en parte durante el viaje de regreso del gobierno de la Generalitat desde los presidios del Puerto de Santa Maria y Cartagena a Barcelona. En ese largo trayecto, de la misma manera que Macià fue vitoreado por Castilla en agosto de 1931, Companys y sus consejeros recibieron múltiples muestras de apoyo de gran parte de la ciudadanía española que veía en ellos unos republicanos encarcelados por defender una República de izquierdas.

\section{CONCLUSIONES}

Como he explicado a lo largo del análisis de las cuatro sesiones del Parlamento autonómico, la política catalana del período republicano de preguerra se basó en una constante dependencia de los cambios existentes en Madrid. Sin una experiencia previa en la tarea de coordinar dos escenarios políticos diferentes, los principales partidos catalanes trazaron una evolución que los situó en una aparente contradicción. Tanto Esquerra como la Lliga, representantes de las grandes variantes del nacionalismo catalán que habían luchado durante treinta años para conseguir la autonomía dentro del Estado Español, una vez llegado el momento no supieron crear un marco político propio.

Ante la dificultad de cubrir con garantía la gran cantidad de puestos de responsabilidad, que tanto en Barcelona como en Madrid obtuvieron los dos partidos, principalmente ERC, los escenarios se utilizaron como armas arrojadizas. Lo que la Lliga no podía conseguir en Cataluña, lo buscaba en Madrid donde al mismo tiempo intentaba poner en evidencia los errores de Esquerra. Por su parte, el partido gobernante en Cataluña, intentaba dar crédito a su actuación política catalana, en base a los apoyos españoles a los que era fiel en las Cortes republicanas buscando el prestigio de Azaña.

Una duplicidad de escenarios políticos que en lugar de provocar una diferenciación cada vez más acentuada, teniendo en cuenta la singularidad de la autonomía catalana, se transformó en una vinculación cada vez más intensa. Una estrecha relación que además cabía vincular a las constantes contradiccio-

46 Domingo, M.: On va Catalunya, Barcelona, Llibreria Catalònia, 1930, p. XVII. 
nes del catalanismo, para con su visión de las relaciones Cataluña-España: no a la búsqueda de la soberanía completa, pero si insistencia en la remodelación de España en estado federal.

Todo esto en un contexto político donde un observador de gran sagacidad como el embajador italiano en Madrid podía decir:

«(...) es cierto que el problema catalán, después del advenimiento de la República, se a agravado y ha venido casi a constituir el problema fundamental del estado español (...). Y esto sin contar que el régimen republicano de España encuentra propiamente en Cataluña su más fuerte baluarte, y que les sería difícil privarse de ella sin correr el riesgo de comprometer su existencia» ${ }^{47}$.

Y es que como expresaba el embajador Raffaele Guariglia, las contradicciones se repartían casi a partes iguales entre la Cataluña autónoma y la República. Por un lado, los catalanistas, una vez descartado históricamente el independentismo, vinculaban su suerte a una República que aún sin ser partidaria de la autonomía, tenía en Cataluña su principal baza. Asi, no era posible concebir una República sin Cataluña, pero tampoco una Cataluña autónoma sin el régimen republicano. Todo esto, además rematado por las vinculaciones izquierdistas con las que nacieron la República y la autonomía que excluyeron del nuevo régimen casi de manera definitiva a la Lliga y las fuerzas derechistas españolas.

De este modo, los años que se sucedieron entre el 14 de abril de 1931 y el 18 de julio de 1936, vieron como el llamado «problema catalán» seguía protagonizando una parte importante de la política española. Por una parte, porqué la mayoría de las fuerzas políticas estatales seguían en contra de la autonomía, así se sucedieron los conflictos de la proclama de Macià, los debates del Estatuto, las constantes discusiones sobre los traspasos, la pugna judicial en el Tribunal de Garantías, el 6 de octubre, la suspensión del Estatuto y su reinstauración en 1936. Pero también porque los partidos catalanes no supieron diferenciar los escenarios parlamentarios totalmente diversos que se vivían en Barcelona o Madrid. Enfrentados en una lucha política fraticida, en nada beneficiosa para nadie, pero quizás general en toda la Europa del periodo de entreguerras, las fuerzas catalanistas abandonaron en gran medida lo que podría haber sido un discurso de consumo interno catalán para buscar en la política española los argumentos que les hicieran con el poder.

La política española utilizada como elemento de propaganda para la opinión pública catalana se erigió en una base imprescindible de la actuación de los partidos catalanistas. Del mismo modo, que las constantes apelaciones a los partidos o instituciones españolas para que intervinieran en la política catalana, principalmente por parte de la Lliga, situaron los debates en el Parlamento autónomo como un apéndice particular de las Cortes republicanas.

47 Guariglia, R.: Primi pasi in diplomazia e rapporti dall'ambasciata di Madrid, 1932-1934, Roma, Edizioni Scientifiche Italiane, 1973, p. 392 